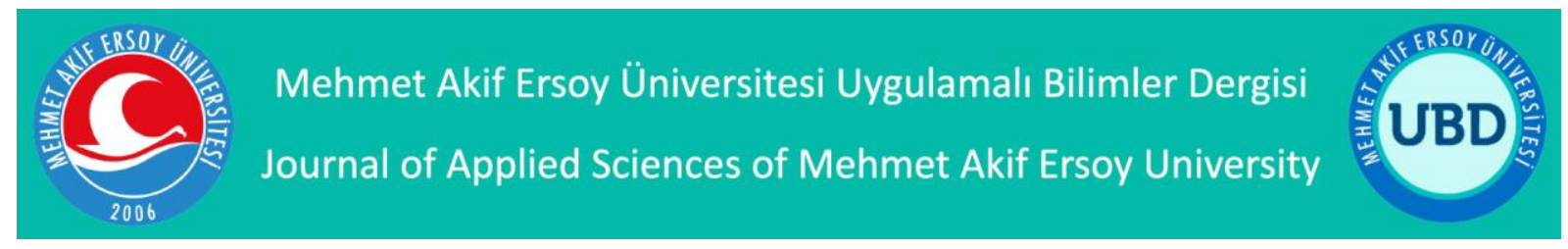

\title{
Nakit Dönüşüm Süresinin Firma Karlılığına Etkisi: Küresel Lojistik Firmaları Üzerine Bir Uygulama ${ }^{1}$
}

\author{
Eyyüp Ensari ŞAHIN ${ }^{*}$ (D) Gizem VERGILI' ${ }^{2}$ \\ ${ }^{1}$ Asst. Prof. Dr., Hitit University, Çorum, Turkey \\ ${ }^{2}$ Research Asst. Dr., Burdur Mehmet Akif Ersoy University, Burdur, Turkey
}

Geliş Tarihi/Received: 26.09.2019

Doi: doi.org/10.31200/makuubd.624946

Kabul Tarihi/Accepted: 01.10.2019

Araştırma Makalesi/Research Article

\section{ÖZET}

Yunanca bir kelime olan "logistikos" kelimesinden gelmekte olan ve Fransizca'dan dilimize geçmiş olan lojistik kelimesi, İngilizce logic ve statistics kelimelerinin birleşiminden meydana gelmektedir. Lojistik, askeri orjinli bir kavram olmakla birlikte işletme başta olmak üzere diğer disiplinlerde de önemli bir kavram haline gelmiştir. İletişim, bilişim ve ulaştırma sektöründe yaşanan hızlı gelişim ve değişime bağlı olarak tüm dünyada lojistik sektörünün önemi artmış ve ülkelerin lokomotif sektörlerinden birisi durumuna gelmiştir. Bu sebeple sektörün yaşanabilecek tüm risklere karşı özellikle finansal açıdan iyi yönetilmesi ve hazırlıklı olması gerekmektedir. Yaşanacak finansal gelişmeler ve beraberinde getireceği risklere karş1 firmaların işletme sermayesi yönetimi oldukça önem arz etmektedir. İşletme sermayesi; nakit ve nakit benzerleri, alacaklar ve stok unsurundan oluşmaktadır. İşletme sermayesinin ve unsurlarının birçok faktörden etkilenmesi, işletmelerin söz konusu kararlarda özenli davranmalarını ve ayrıntılı analizler yapmalarını gerektirmektedir. Bu çalışmada "The Journal Of Commerce" tarafından yapılan sıralamaya göre dünyanın 50 büyük lojistik firması üzerine 2009q1-2017q4 yılları için panel veri analizi yapılmıştır. Çalışmanın verilerine Datastream Thomson Reuters veri tabanından ulaşılmıştır. Çalışmanın sonucunda nakit dönüşüm süresi ile firma karlılığı arasında negatif ve anlamlı bir ilişki bulunmuştur.

Anahtar kelimeler: Lojistik, Nakit Dönüşüm Süresi, ROA.

JEL Kodları: C33, O16, L90.

1 Bu çalışma "Innovation and Global Issues Congress IV" kongresinde bildiri olarak sunulmuştur.

* Sorumlu yazar/Corresponding author

E-mail/e-ileti: eyupensarisahin@ @hitit.edu.tr 
Şahin, E. E. \& Vergili, G.

\title{
The Effect of Cash Conversion Cycle on Firm Profitability: An Application on Global Logistics Companies
}

\begin{abstract}
The word "logistikos" which comes from Greek and passes from French to our language, consists of the combination of English words logic and statistics. Although logistics is a military-oriented concept, it has become an important concept in other disciplines, especially in business. Depending on the rapid development and change experienced in communication, information and transporation sectors, the importance of logistic sector has increased and become one of the locomotive sector in the world. For this reason, the sector should be financially well managed and prepared to all possible risks. Working capital management of firm is very important against the risks which the financial developments bring with. In this study, panel data analysis was performed for 2009q1-2017q4 world's 50 largest logistics companies which are sorted by "The Journal Of Commerce". Data of study was obtained on Thomson Reuters Datastream. As a result of the study, a negative and significant relationship was found between cash conversion cycle and firm profitability.
\end{abstract}

Keywords: Logistics, Cash Conversion Cycle, ROA.

\section{GíRIŞ}

Firmalar genellikle işletme sermayesi yönetimini nakit üretmek için stratejik bir öncelik olarak düşünmektedir. İşletme sermayesi yönetimi kapsamında nakdin, alacakların, stokların ve kısa vadeli borçların yönetilmesi esastır. Bu nedenle özellikle likidite yönetimi dönen varlıklar ve kısa vadeli yabancı kaynaklar yönetimi ile ilgili riskler ve getiriler arasında yoğun bir değişime yol açtığı için finansal yönetimin alanlarından biri olmuştur. Nakit dönüşüm süresi likidite yönetimi ile ilgili riskleri ve getirileri değerlendirmek ve ölçmek için en yaygın kullanılan ölçümdür. Böylece işletme sermayesi yönetiminde kilit faktör olan nakit dönüşüm süresinin önemi de artmaktadır.

İşletmeler nakit yönetimi uygulamalarında âtıl fonu gerekli olacağı zamana kadar farklı finansal enstrümanlarla değerlendirmek isterler. Bu süreçte önemli olan likit kalabilmek ve borcun maliyetinde bir artış yaratmadan olabildiğince borcu vade sonuna ödemek temeldir. İşletmeler farklı faaliyet alanına göre değişmekle birlikde elindeki nakit hammaddye, hammadde yarı mamule, yarı mamul mamule satış sonrası alacaklar, alacakların tahsil edilmesi tekrar nakde dönüştüğü bir ekosistem içerisinde Nakit dönüşüm süresini tamamlarlar. Nakit 
dönüşüm süresi, stokta geçen süre ile ticari alacakların tahsilinde geçen sürelerin toplamından, ticari borçların ödenme süresinin çıkarılmasıyla bulunur. Nakit dönüşüm süresi üç bileşenden oluşmaktadır: "alacak tahsil süresi”, "stok tüketim süresi” ve "kısa vadeli borç ödeme süresi”.

Alacak tahsil süresi bir firmanın tedarik zinciri ekosisteminde alt zinciri (downstream) yönetme gücünü göstermektedir. Kısa vadeli borç ödeme süresi ise tedarik zincirinde bir üst zinciri (upstream) yönetebilme kabiliyetini göstermektedir (Luo vd., 2009: 4). Nakit dönüşüm süresinin olabildiğince kısaltılması işletmenin finansal performansını etkilemektedir. Çünkü işletmelerde nakit dönüşüm süresinin uzun olması kârlılık ile negatif korelasyon durumunu ortaya çıkarmaktadır.

Tüm sektörleri kapsayan tek bir optimum nakit dönüşüm süresinden bahsedilemez. Her sektörün stok tutma süreleri, alacak tahsilat politikaları ve borç ödeme süreleri ülkeden ülkeye, ölçekten ölçeğe, piyasa koşullarına göre farklılık gösterebilmektedir. Ancak nakit dönüşüm süresinin kısa olması tercih edilen bir durumdur (Farris vd., 2005: 114)

Çalışmamızda lojistik sektörünün nakit dönüşüm süresinin firma karlılığına etkisi ele alınmıştır. The Journal Of Commerce" tarafından yapılan sıralamaya göre dünyanın 50 büyük lojistik firması seçilmiş, tamamında gerekli veriye ulaşılamadığı için bu sayı 33 lojistik firmasıyla sınırlı kalmıştır. 2009q1-2017q4 dönemine ait çeyrekli veriler datastream veri tabanından sağlanmıştır.

\section{LITERATÜR TARAMASI}

Literatürde özellikle işletme sermayesi yönetiminin karlılığa etkisi kapsamında pek çok çalışma yer almaktadır. İşletme sermayesi etkinlik ölçümü için nakit dönüşüm süresini ilk defa Gitman 1974 yılında yaptığı çalışmasında kullanmıştır (Silva, 2011: 4).

Lazarids ve Tryfonids (2006), Atina Borsa'sında işlem gören 131 şirketin 2001-2004 dönemini kapsayan verileriyle çalışma sermayesi yönetimi ve karlılık arasındaki ilişkiyi inceledikleri çalışmalarında nakit dönüşüm süresi ve karlılık arasında negatif ilişki olduğunu tespit etmişlerdir.

Gill, Biger ve Mathur (2010), Newyork Borsası (NYSE)'nda işlem gören 88 firma için 2005-2007 dönemini kapsayan verileriyle çalışma sermayesi yönetimi ve karlılık arasındaki ilişkiyi inceledikleri çalışmalarında, nakit dönüşüm süresi ile karlılık arasında pozitif ilişki bulmuşlardır. 
Şahin, E. E. \& Vergili, G.

Meder Çakır (2013), İMKB imalat sektöründe faaliyet gösteren 52 işletmenin 20002010 dönemine ait verileriyle, nakit dönüşs süresinin işletme karlılığına etkisini panel veri ile analiz etmiştir. Analiz sonucunda imalat sanayi genelinde beklenilenin aksine işletmelerin nakit dönüş süresini artırarak karlılıklarını artırabilecekleri ortaya çıkmıştır. Kimya ve taş alt sektörlerinde ise karlılık ile nakit dönüş süresi arasında ters yönlü bir ilişki tespit edilmiştir.

Anser ve Malik (2013), Pakistan'ın Karachi Borsası imalat sektöründe faaliyet gösteren firmaların 2007-2011 dönemları arasında nakit dönüşüm süresi ile karlılıkları arasındaki ilişkiyi araştırmışlardır. Çalışmalarında, nakit dönüşüm süreleri ile hem varlık karlılığı hem de özsermaye karlılığı arasında ters yönlü ilişki bulmuşlardır.

Upadhyay, Sen ve Smith (2015), Washington Eyalet'inde bulunan hastanelerin 20022011 dönemini kapsayan verileriyle nakit dönüşüm süresi ve karlılık üzerine yaptıkları çalışmaları sonucunda hastane yöneticilerinin karlılığı artırmak için nakit dönüşüm sürelerini kısaltmaları gerektiği sonucuna ulaşmışlardır.

Topaloğlu ve Nur (2016), Borsa İstanbul (BIST) Kurumsal Yönetim Endeksi’nde faaliyet gösteren 18 şirketin 2010-2014 yılları arasında nakit dönüşüm sürelerinin hem varlık karlılığa hem de özsermaye karlılığına etkisini incelemişlerdir. Analiz sonucunda sadece varlık karlılığı ile nakit dönüşüm süresi arasında anlamlı ve pozitif bir ilişkyei rastlanırken, özsermaye karlılığı ile nakit dönüşüm süresi arasında herhangi bir ilişki tespit edilememiştir.

Öztürk ve Vergili (2018), BIST' da işlem gören maden firmalarının 2009q4-2015q3 dönemlerine ait veriler ile işletme sermayesi yönetimin karlılık üzerinde etkisini ölçmeye çalışmışlardır. Maden sektörü işletme sermayesi unsurlarından olan nakit dönüşüm süresi ile karlılık arasında istatistiksel olarak anlamlı bir ilişsi tespit edilememiştir.

Topak (2018), BIST Ticaret Endeksi (XTCRT)'nde yer alan şirketlerin 2004-2017 dönemlerine ilişkin verilerle çalışma sermayesi yönetiminin karlılığa etkisini incelediği çalışmasında, nakit önüşüm süresinin ROA üzerinde negatif ve istatistiki olarak anlamlı bir ilişki olduğu sonucuna ulaşmıştır.

\section{LOJISTIIK SEKTÖRÜ VE MEVCUT DURUMU}

Literatürde de bahsedildiği gibi İngilizce logic ve statistics kelimelerinin birleşiminden meydana gelen lojistik için eygun tanım "seven rights (yedi doğru)" tanımıdır. Lojistiğin somut ve soyut boyutlarını içeren söz konusu tanıma göre; istenilen ürünün veya hizmetin, istenilen 
miktarda, uygun şartlarda, gerektiği yerde, doğru zamanda, uygun maliyetle, müşterinin kullanımına sunulmasıdır (Rushton vd, 2014: 16). Uluslararası Taşımacılık ve Lojistik Derneği'ne (UTIKKAD) göre lojistik, “Ürün ve hizmet yönetimi ve dağıtım süreçlerini içine alan, taşıması başlayan stoklar ile beklemede olan stokların yönetimi ile kullanım ömrü biten ürünlerin yeniden ürün haline dönüştürülmesi işlevini de içine alan, ürünlerin tedarik zinciri süreci boyunca depolanması, taşınması ve elleçleme işlemlerinin planlanması ve gerçekleştirilmesi ile ilgili faaliyetlerin bütünü” olarak tanımlanmaktadır. ${ }^{21}$

Lojistik kavramı ilk olarak askeri faaliyetler, sonrasında da iş dünyasında kullanılmıştır. Albay Chauncey Baker (1905) lojistiği, askeri araç gereçler ve personelin taşınması, tedariki, bakım ve onarımı faaliyetleri olarak tanımlamıştır. Dünyada hızla büyüyen lojistik sektörü ülke ekonomileri ve dünya ekonomisi açısından son derece önemli olup, önemini her geçen gün daha da artırmaktadır. Globalleşen dünyada ticaretin gelişimi lojistiğe olan talebi artırmıştır. Lojistik süreçlerin firmalar için önem kazanması küresel pazarlarda rekabet üstünlüğü sağlaması bakımından da önem taşımaktadır. Ülke ekonomileri açısından ise ticari ve toplumsal hayata sağladıkları katkı ve GSMH içinde yarattıkları katma değerle önem kazanmıştır. 2016 yılı verilerine göre ABD'de lojistik faaliyetler GSMH'ın yaklaşık \%7,5'ini oluşturmaktadır ${ }^{22}$. Müşteri odaklı faaliyetlerin gerçekleştirilmesi günümüzde bilişim tabanlı yönetim uygulamaları ve yaklaşımlarında yaşanan değişimleri hızlandırmıştır (Mentzer vd., 2004: 610). Özellikle tamamlanan süreçlerin katma değer yaratması beklenmekte, katma değeri düşük olan işlemlerin sıfıra indirilmesi çabası içine girilerek değer analizi çalışmaları yapılmaktadır.

\section{ARAŞTIRMA}

\subsection{Araştırmanın Amacı ve Önemi}

Çalışmada küresel ölçekte farklı borsalarda işlem gören ve dünyanın en büyük 50 lojistik firmasının Nakit Dönüşüm Süresi (NDS), Büyüklük ve Kaldıraç ile Karlılık arasındaki ilişkinin tespit edilmesi amaçlanmıştır. Çalışmanın lojistik sektöründe küresel ölçekte faaliyet gösteren firmalara uygulanması çalışmayı literatüre yapacağı katkılardan dolayı önemli kilmaktadir.

\footnotetext{
21 http://www.utikad.org.tr (25.10.2018)

$22 \mathrm{https}$ ://www.selectusa.gov/logistics-and-transportation-industry-united-states (05.11.2018)
} 
Şahin, E. E. \& Vergili, G.

\subsection{Araștırma Verileri}

Çalışmanın verileri Datastream veri tabanından alınmış olup, lojistik sektöründe faaliyet gösteren dünyanın en büyük 50 lojistik firmasının 2009q1 ile 2017q4 yılları arasındaki çeyrek dönemlerini kapsamaktadır. Analize dâhil edilen firmalar Ek-1'de verilmiştir. Ayrıca dünyanın farklı borsalarında ve farklı risk düzeylerinde işlem gören firmaların farklı risk kategorisinde olduğundan kümeleme analizi yapılmıştır. Kümele analizinde Dünya Bankası tarafından açıklanan politik risk değerleri kullanılmış olup Ek 2'de verilen Dendogram grafiğine göre firmalar iki farklı risk grubuna ayrılmıştır. Kümeleme analizinde kullanılan politik risk endeksi değerleri Ek 3'te verilmiştir. Çalışmada kullanılan ve gelir sıralamasına göre dünyanın 50 en büyük Lojistik firmasının 17'sinin verilerine ulaşılamamıştır. Bu nedenle çalışmada kullanılan toplam firma sayısı 33’tür. Verilerine ulaşılamayan firmalar analize dahil edilmemiştir.

Çalışmada bağımlı değişkenimiz olarak ROA varlık karlılığı kullanılmış, bağımsız değişken olarak da pek çok çalışmada da kullanıldı̆̆ı gibi CCC(Cash Conversion Cycle-Nakit Dönüşüm Süresi-NDS), SIZE (Satışların Doğal Logaritması) büyüklük olarak ve LEV kaldıraç oranı kullanılmıştır (Anser ve Malik, 2013; Keskin ve Gökalp, 2016).

Tablo 1. Çalışmada kullanılan bağımlı ve bağımsız değişkenler

\begin{tabular}{|c|l|l|}
\hline \multirow{2}{*}{$\begin{array}{c}\text { BAĞIMLI } \\
\text { DEĞISSTKN }\end{array}$} & DEĞIŞKENLER & FORMÜL \\
\cline { 2 - 3 } & $\boldsymbol{R O A}$ & $\begin{array}{l}\text { Net Profit/Average Total Assets } \\
\text { Net Kar/Ortalama Toplam Varlıklar }\end{array}$ \\
\hline \multirow{2}{*}{$\begin{array}{c}\text { BAĞIMSIZ } \\
\text { DEĞIŞKEN }\end{array}$} & SIZE & $\begin{array}{l}\text { Nakit Dönüşüm Süresi(NDS)=Stok Tutma Süresi+ Alacakların } \\
\text { Tahsil Süresi-Borçların Ödenme Süresi }\end{array}$ \\
\cline { 2 - 3 } & LEV & Satışların Doğal Logaritması \\
\cline { 2 - 3 } & Ortalama Toplam Borç/ Ortalama Toplam Varlık \\
\hline
\end{tabular}

\subsection{Araştırmanın Yöntemi}

Çalışmada, literatürde sıklıkla kullanılmış olan Panel Regresyon modeli kullanılacaktır. Panel Regresyon, zamana dayalı yatay kesit serilerini kullanarak değişkenler arasındaki ilişkilerin tahmin edilmesinde kullanılan bir yöntem olarak tanımlanabilmektedir (Gujarati, 2003:636).

Çalışmada kullanılan Panel Regresyon Modelleri aşağıdaki gibidir: 
Yüksek Riskli Firmalar ROA $=\alpha_{i}+\beta_{i 1}(C C C)+\beta_{i 2}($ LnSize $)+\beta_{i 3}(L E V)+\varepsilon_{i} \varepsilon_{i}$ Düşük Riskli Firmalar ROA $=\alpha_{i}+\beta_{i 1}(C C C)+\beta_{i 2}($ LnSize $)+\beta_{i 3}(L E V)+{ }^{\varepsilon_{i}} \varepsilon_{i}$

Araştırmanın diğer yöntemi ise Kümeleme analizidir. Kümeleme analizi, farklı ülkede faaliyet gösteren 33 lojistik firmasının homojen bir yapıya kavuşmasını sağlamak ve firmaların karşı karşıya kaldıkları risk boyutuna göre değerlendirme yapmak için kullanılmıştır. Çalışmada kullanılan risk değerlerinin elde edilebilmesi için on farklı risk unsuru altı farklı risk bölümüne ayrılarak oluşturulan endeks değerleri dikkate alınmıştır. Kümeleme analizi için kullanılan değişskenler ve açıklamaları aşağıdaki tabloda gösterilmiştir.

Tablo 2. Çalışmada kullanılan bağımlı ve bağımsız değişkenler

\begin{tabular}{|c|c|}
\hline RİSK TÜRÜ & AÇIKLAMA \\
\hline Anayasa ve Hukuksal Düzen & $\begin{array}{l}\text { Bu başlık altında ülkelere ait } \\
\text { • Devlet yönetimi ve politikalara ordunun } \\
\text { etkisi } \\
\text { • Ülkenin demokratik hesap verebilirliği }\end{array}$ \\
\hline Politik İstikrar ve Şiddet & $\begin{array}{c}\text { Bu başlık altında ülkelere ait } \\
\text { - Hükümet istikrarı } \\
\text { - İç karışıklıklar } \\
\text { - Diş karışıklıklar } \\
\text { - Etnik gerilimler }\end{array}$ \\
\hline Hükümet Kalitesi & $\begin{array}{l}\text { Bu başlık altında ülkelere ait } \\
\bullet \quad \text { Bürokrasi kalitesi }\end{array}$ \\
\hline Yatırım Profili & $\begin{array}{l}\text { Bu başlık altında ülkelere ait } \\
\bullet \quad \text { Ülkenin yatırım profili }\end{array}$ \\
\hline Demokratikleşme & $\begin{array}{l}\text { Bu başlık altında ülkelere ait } \\
\qquad \quad \text { Hukuk Düzeni } \\
\text { • Hukukun Üstünlüğü }\end{array}$ \\
\hline Yolsuzluk & $\begin{array}{l}\text { Bu başlık altında ülkelere ait } \\
\bullet \quad \text { Yolsuzluk }\end{array}$ \\
\hline
\end{tabular}

Kaynak: http://info.worldbank.org.

\subsection{Araştırmanın Bulguları}

\subsubsection{Tanımlayıcı istatistikler}

Bağımlı ve bağımsız değişkenlere ait tanımlayıcı istatistikler panel veri formunda hesaplanmıştır. Sonuçlar aşağıdaki tabloda sunulmuştur. 
Şahin, E. E. \& Vergili, G.

Tablo 3. Tanımlayıcı istatistikler

\begin{tabular}{|l|c|c|c|c|c|c|c|c|}
\hline & \multicolumn{4}{|c|}{ Yüksek Riskli Firmalar } & \multicolumn{4}{c|}{ Düşük Riskli Firmalar } \\
\hline & ROA & CCC & SIZE & LEV & ROA & CCC & SIZE & LEV \\
\hline Mean & 2.3455 & 2.866 & 3.567 & 0.126 & 4.339 & 3.351 & 3.542 & -0.456 \\
\hline Median & 3.789 & 1.945 & 0.412 & 0.956 & 2.207 & 3.500 & 5.091 & 0.879 \\
\hline Maximum & 10.728 & 0.063 & 7.912 & 4.308 & 9.257 & 5.257 & 4.913 & 1.345 \\
\hline Minimum & 0.3456 & 0.181 & 0.401 & 0.056 & 0.108 & 0.090 & 2.802 & 0.8756 \\
\hline Std. Dev. & 2.5678 & 1.158 & 0.934 & 0.456 & 1.610 & 2.696 & 1.792 & 0.312 \\
\hline Skewness & -1.4567 & -2.235 & 1.497 & -0.713 & -1.079 & 0.050 & -2.329 & 0.5432 \\
\hline Kurtosis & 2.0098 & 0.768 & 6.040 & 2.192 & 2.134 & 2.412 & 3.419 & 3.5678 \\
\hline
\end{tabular}

Tablo 4. Korelasyon matrisi

\begin{tabular}{|c|c|c|c|c|c|c|c|c|}
\hline & \multicolumn{3}{|c|}{ Yüksek Riskli Firmalar } & \multicolumn{3}{c|}{ Düşük Riskli Firmalar } \\
\hline & ROA & CCC & SIZE & LEV & ROA & CCC & SIZE & LEV \\
\hline ROA & 1 & & & & 1 & & & \\
\hline CCC & 0,795 & 1 & & & 0,789 & 1 & & \\
\hline SIZE & 0,858 & 0,812 & 1 & & 0,653 & 0,653 & 1 & \\
\hline LEV & 0,839 & 0,859 & 0,763 & 1 & 0,921 & 0,634 & 0,829 & 1 \\
\hline
\end{tabular}

\subsubsection{Durağanlık testleri}

Bu çalışmada durağanlık testi Augmented Dickey- Fuller, Pesaran and Shin W-stat, Phillips - Perron ve Levin, Lin \& Chu testi ile test edilmiştir. Verilerin birinci seviyeden farkları alınarak durağan hale getirilmiştir. Tablo-6' da durağanlık testlerinin sonuçları yer almaktadır. Teste tabi tutulan değişkenlerin gecikme sayısı, Schwarz Bilgi Kriteri kullanılarak belirlenmiştir.

Tablo 5. Değişkenlere ilişkin durağanlık testleri

\begin{tabular}{|c|c|c|c|c|c|c|c|c|}
\hline \multirow{2}{*}{ Değişkenler } & \multicolumn{2}{|c|}{$\begin{array}{c}\text { Augmented } \\
\text { Dickey- Fuller }\end{array}$} & \multicolumn{2}{|c|}{$\begin{array}{c}\text { Im, Pesaran and Shin W- } \\
\text { stat }\end{array}$} & \multicolumn{2}{|c|}{ Phillips - Perron } & \multicolumn{2}{|c|}{ Levin, Lin \& Chu } \\
\hline & $\begin{array}{c}\mathrm{t} \\
\text { istatistik }\end{array}$ & $\underset{\text { değeri }}{\mathrm{p}}$ & $\begin{array}{c}\mathrm{t} \\
\text { istatistik }\end{array}$ & $\underset{\text { değeri }}{\mathrm{p}}$ & $\begin{array}{c}\mathrm{t} \\
\text { istatistik }\end{array}$ & $\underset{\text { değeri }}{\mathrm{p}}$ & $\begin{array}{c}\mathrm{t} \\
\text { istatistik }\end{array}$ & $\begin{array}{c}\mathrm{P} \\
\text { değeri }\end{array}$ \\
\hline $\mathrm{ROA}$ & -3.119 & 0.0000 & -3.087 & 0.0000 & 10.001 & 0.0000 & -4.657 & 0.0000 \\
\hline $\mathrm{CCC}$ & -3.239 & 0.0000 & -2.602 & 0.0000 & 9.194 & 0.0000 & -3.065 & 0.0000 \\
\hline SIZE & 8.810 & 0.0000 & -4.560 & 0.0000 & 6.347 & 0.0000 & -4.713 & 0.0000 \\
\hline LEV & 12.367 & 0.0000 & -10.430 & 0.0000 & -4.490 & 0.0000 & -8.407 & 0.0000 \\
\hline
\end{tabular}


Tabloda görüldüğü üzere hiçbir değişkenin olasılık değeri 0,05 'den büyük çıkmadığı sonucuna ulaşılmıştır. Diğer bir ifade ile verilerimiz durağandır. Sonuç olarak "Nakit Dönüşüm Süresinin Karlılık Üzerine Etkisini” incelemeyi amaçladığımız çalışmada verilerin durağan olması bu modelin kurulmasını elverişli hale getirmiştir.

\subsubsection{Araştırma bulguları}

Panel veri analizi iki farklı tür göstermektedir. Bunlardan ilki sabit etkiler modeli (fixed effects) olup ikincisi de rassal etkiler modelidir (random effects). Araştırmada Panel Veri Sabit etkili (fixed effect) modeli kullanılmıştır. Bu modelin seçiminde Hausman Testi kullanılmış ve rassal etkili (random effect) panel veri analizine göre daha uygun sonuç verdiği ortaya çıkmıştır. Hipotezler ise aşağıdaki şekildedir;

$\mathrm{H}_{0}=$ Rassal Etkili Panel Veri Analizi daha uygun sonuç verir,
$\mathrm{H}_{1}=$ Rassal Etkili Panel Veri Analizi daha uygun sonuç vermez.

Tablo 6. Yüksek riskli firmalar için hausman test sonuçları

\begin{tabular}{|l|c|c|c|}
\hline & \multicolumn{3}{|l|}{ Correlated Random Effects - Hausman test } \\
\hline Test Summary & Chi-Sq. Statistic & Chi - Sq. f. & Prob. \\
\hline Cross- section random & 20.001 & 9 & 0.0000 \\
\hline
\end{tabular}

Tablo 7. Düşük riskli firmalar hausman test sonuçları

\begin{tabular}{|l|c|c|c|}
\hline & \multicolumn{3}{|c|}{ Correlated Random Effects - Hausman test } \\
\hline Test Summary & Chi-Sq. Statistic & Chi - Sq. f. & Prob. \\
\hline Cross- section random & 34.456 & 8 & 0.0000 \\
\hline
\end{tabular}

Tablo 8. Yüksek riskli firmalar panel veri analiz sonuçları

\begin{tabular}{|c|c|c|c|c|}
\hline Bağımlı Değişken & \multicolumn{4}{|l|}{ ROA } \\
\hline Metot & \multicolumn{4}{|c|}{ Panel Sabit Etkili Model } \\
\hline Örneklem y1lı & \multicolumn{4}{|c|}{$2009 q 4-2017 q 4$} \\
\hline Variables & Coefficient & Std. Error & t-Statistic & Prob. \\
\hline $\mathbf{C}$ & 12.4567 & 0.3456 & 3.45 & 0.003 \\
\hline $\mathrm{CCC}$ & -0.00034 & 0.000056 & -3.76 & 0.002 \\
\hline SIZE & -0.007124 & 0.003490 & -1.09 & 0.456 \\
\hline LEV & -0.00812 & 0.0812 & 4.21 & 0.987 \\
\hline$\overline{A d j .} R^{2} R^{2}$ & 0.78 & & & \\
\hline F-statistic & 12.56 & & & \\
\hline Prob(F-statistic) & 0.0008 & & & \\
\hline Durbin-Watson & 1.879 & & & \\
\hline
\end{tabular}


Kümele analizi sonucunda Ek 2'de yer alan Dendogram grafiği sonuçlarına göre yüksek riskli kategoride bulunan firmaların düzeltilmiş $\mathrm{R}^{2}$ 'si \%78 çıkmıştır. Ayrıca $\mathrm{F}$ olasıllık değeri (0.000) kurulan modelin anlamlı olduğunu göstermektedir. Yapılan analiz sonucunda ROA ile CCC arasında negatif ve istatistiksel olarak anlamlı bir sonuç bulunmuştur. Diğer bağımsız değişkenler ile ROA arasında istatistiksel olarak bir ilişki bulunamamıştır.

Tablo 9. Düşük riskli firmalar panel veri analiz sonuçları

\begin{tabular}{|c|c|c|c|c|}
\hline Bağımlı Değişken & \multicolumn{4}{|l|}{ ROA } \\
\hline Metot & \multicolumn{4}{|c|}{ Panel Sabit Etkili Model } \\
\hline Örneklem y1lı & \multicolumn{4}{|c|}{$2009 q 4-2017 q 4$} \\
\hline Variables & Coefficient & Std. Error & t-Statistic & Prob. \\
\hline $\mathrm{C}$ & 45.8134 & 0.29064 & 1.77 & 0.145 \\
\hline $\mathrm{CCC}$ & -0.00234 & 0.00481 & -3.90 & 0.000 \\
\hline SIZE & -0.01359 & 0.2209 & -0.45 & 0.654 \\
\hline LEV & 0.49212 & 0.21092 & 2.06 & 0.054 \\
\hline Adj. $R^{2} R^{2}$ & 0.7509 & & & \\
\hline F-statistic & 15.39023 & & & \\
\hline Prob(F-statistic) & 0.0000 & & & \\
\hline Durbin-Watson & 2.0001 & & & \\
\hline
\end{tabular}

Kümele analizi sonucunda Ek 2'de yer alan Dendogram grafiği sonuçlarına göre düşük riskli kategoride bulunan firmaların düzeltilmiş $\mathrm{R}^{2}$ 'si \% 75 çıkmıştır. Ayrıca F olasılık değeri (0.000) kurulan modelin anlamlı olduğunu göstermektedir. Yapılan analiz sonucunda ROA ile CCC arasında negatif ve anlamlı bir sonuç bulunmuştur. Diğer bağımsız değişkenler ile ROA arasında istatistiksel olarak bir ilişki bulunamamıştır. Kurulan iki modelde de literatür ile örtüşen sonuçlar bulunmuştur. Analizde kullanılan firmalar her ne kadar farklı risk kategorilerinde yer alsa da gelir bazlı yapılan sıralamaya göre en büyük firmalar olması düşük nakit dönüşüm süresini yakaladıklarını göstermektedir. Buna bağlı olarak da firmaların karlılıkları yüksek çıkmaktadır.

\section{SONUÇ}

Firmalar için çalışma sermayesi kapsamında nakit yönetimi çok önemlidir. Nakit dönüşüm süresinin firma karlılığı üzerindeki etkisini ölçmek için panel veri analizi kullanılmıştır. "The Journal Of Commerce" tarafından yapılan sıralamaya göre dünyanın 50 büyük lojistik firması içerisinden 2009q1-2017q4 dönemini kapsayan, verilerine eksiksiz ulaşılabilen 33 tanesi üzerine analiz yapılmıştır. Firmaların dünyanın farklı borsalarında işlem görmesi ve farklı risk düzeylerine sahip olması nedeniyle Dünya Bankası tarafından açıklanan politik risk değerleri kullanılarak öncelikle kümeleme analizi yapılmıştır. Örneklemimizi 
oluşturan lojistik firmaları kümeleme analizi ile düşük riskli ve yüksek riskli firmalar olarak ikiye ayrılarak analize tabi tutulmuştur. Çalışmada bağımlı değişken olarak varlık karlılığı olarak ROA alınmış, bağımsız değişken olarak nakit dönüşüm süresi CCC, satışların büyüklüğü SIZE ve kaldıraç oranı DEBT değişkenleri kullanılmıştır. F olasılık değerine göre anlamlı bulunan her iki modelde de varlık karlılığı ROA ile nakit dönüşüm süresi CCC arasında istatistiksel olarak anlamlı ve negatif ilişki bulunmuştur. Bu sonuç literatürdeki pek çok çalışma ile tutarlıdır. Diğer bağımsız değişkenler ile ROA arasında istatistiksel olarak bir ilişki bulunamamıştır. Örneklemimizi oluşturan lojistik sektörü için stok tutma süresi ve alacakların tahsil süresi kısaldıkça ve borç ödeme süresi uzadıkça nakit dönüşüm süreleri kısalacak ve böylece karlılıkları artacaktır. Aksi takdirde nakit dönüşüm süresinin uzaması karlılıklarının azalmasına neden olacaktır. Negatif yönlü ilişkiyi göz önünde bulundurarak uygun nakit yönetimi politikası sergilendiğinde artan karlılıkların yakalanması mümkündür. Değișen dünya ekonomisi, teknolojinin ilerlemesi ve lojistik sektörüne olan ihtiyacın artması ile lojistik firmaları karlılıklarını artırabilmek için sektör için uygun olan en kısa nakit dönüşüm süresini belirleyip uygulamaya koyması gerekmektedir. İlerleyen çalışmalarda nakit dönüşüm süresini oluşturan unsurlar için de analiz yapılarak stok tutma süresi, alacak tahsil süresi ve borç ödeme süresinden hangisinin daha etkili olduğu belirlenerek karlılığı artırmak için stratejiler geliştirilebilir.

\section{REFERENCES / KAYNAKLAR}

Anser, R. \& Malik, Q. A. (2013). Cash conversion cycle and firms' profitability-a study of listed manufacturing companies of Pakistan. IOSR Journal of Business and Management, 8(2), 83-87.

Farris II, M. T., Hutchison, P. D. \& Hasty, R. W. (2005). Using cash-to-cash to benchmark service industry performance. The Journal of Applied Business Research, 21(2), 113-124.

Gill, A., Biger, N. \& Mathur, N. (2010). The relationship between working capital management and profitability: Evidence from The United States. Business and Economic Journal, 10, 1-9.

Gülenç, İ. F. \& Karagöz, B. (2008). E-lojistik ve Türkiye’de e-lojistik uygulamaları. Kocaeli Üniversitesi Sosyal Bilimler Enstitüsü Dergisi, (15), 73-91.

Keskin R. \& Gökalp, F. (2016). Çalışma sermayesinin firma karlılığg üzerine etkisi: Panel veri analizi. Doğuş Üniversitesi Dergisi, 17(1), 15-25.

Lazaridis, I. \& Tryfonidis, D. (2006). Relationship between working capital management and profitability of listed companies in the athens stock exchange. Journal of Financial Management and Analysis. 19(1), 26-35.

Luo, MM, Lee, JJ-Y \& Hwang, Y. (2009). Cash conversion cycle, firm performance and stock value. Current Draft at Workshop, 1-27. 
Şahin, E. E. \& Vergili, G.

Meder Çakır, H. (2013). Nakit döngüsünün firma karlılığına etkisinin sektörel analizi. Journal of Yasar University. 30(8), 4948-4965.

Mentzer, J. T., Min, S. \& Michelle Bobbitt, L. (2004). Toward a unified theory of logistics. International Journal of Physical Distribution \& Logistics Management, 34(8), 606-627.

Öztürk, M. B. \& Vergili, G. (2018). The effects of working capital management on mining firm's profitability: Emprical evidence from an emerging market. Financial Management from an Emerging Market Perspective. IntechOpen: Croatia, Chapter 10, 189-204.

Rushton, A., Croucher, P. \& Baker, P. (2014). The handbook of logistics and distribution management: Understanding the supply chain. Kogan Page Publishers.

Silva, F. (2011). Effects of working capital management on the profitability of Portuguese manufacturing firms (Master thesis). Universidade do Minho.

Topak, M. S. (2018). Çalışma sermayesi yönetiminin karlılığa etkisi: BIST ticaret endeksi üzerine bir araştırma. Mali Çözüm Dergisi, 148, 71-93.

Topaloğlu, E. E. \& Nur, T. (2016). Nakit dönüşüm süresinin finansal performansa etkisi: Kurumsal yönetim endeksinde bir uygulama. Akademik Bakış Uluslararası Hakemli Sosyal Bilimler Dergisi, 53, 304-317.

Upadhyay, S., Sen, B. \& Smith, D. G. (2015). The cash conversion cycle and profitability: A study of hospitals in the state of Washington. Journal of Healthcare Finance, 41(4), 1-9.

http://www.utikad.org.tr, Erişim tarihi: 25.10.2018

http://www.lojisturk.net/guncel/lojistik-tanimi-tarihsel-gelisimi-1341827844h.html, Erişim tarihi: 25.10.2018

https://www.selectusa.gov/logistics-and-transportation-industry-united-states, Erişim tarihi: 05.11.2018 
EK 1. Çalışmada kullanılan firmalar

\begin{tabular}{|c|c|c|c|c|c|c|c|c|c|}
\hline & & \multicolumn{3}{|c|}{ LOW RISK } & & & \multicolumn{3}{|c|}{ HİGH RISK } \\
\hline & RANK & Firm & Country & $\begin{array}{l}\begin{array}{l}\text { Revune } \\
\text { (USD } \\
\text { Millions) }\end{array} \\
\end{array}$ & & Rank & Firm & Country & $\begin{array}{l}\begin{array}{l}\text { Revune } \\
\text { (USD } \\
\text { Millions) }\end{array} \\
\end{array}$ \\
\hline 1 & 1 & DHL Log. & Germany & 30.775 & 1 & 5 & DSV & Denmark & 11.355 \\
\hline 2 & 3 & DB Sechenker Log. & Germany & 17.738 & 2 & 30 & Damco & Denmark & 2.668 \\
\hline 3 & 11 & DACHSER & Germany & 6.826 & 3 & 8 & CEVA Log. & Netherlands & 6.994 \\
\hline 4 & 42 & Fiege Log. & Germany & 1.635 & 4 & 12 & Sinotrans & Chine & 6.662 \\
\hline 5 & 4 & Robinson Worl Wide & USD & 13.503 & 5 & 37 & Kerry Log. & Hong Kong & 2.167 \\
\hline 6 & 6 & XPO Log. & USD & 10.352 & 6 & 20 & Agility Log. & Kuwait & 3.909 \\
\hline 7 & 7 & UPS SCS & USD & 7.981 & 7 & 23 & Samsung SDS & S. Korea & 3.688 \\
\hline 8 & 10 & J.B Hunt & USD & 6.828 & 8 & 28 & Pantos & S. Korea & 2.816 \\
\hline 9 & 25 & FEDEx & USD & 3.294 & 9 & 34 & CJ Korea Exp. & S. Korea & 2.308 \\
\hline 10 & 32 & BDP Int. & USD & 2.384 & 10 & 39 & Imperial Log. & S. Africa & 1.881 \\
\hline 11 & 36 & Transplace & USD & 2.181 & 11 & 21 & Toll group & Australia & 3.790 \\
\hline 12 & 46 & OIA Global & USD & 1.266 & 12 & 13 & SNCF Geodis & France & 5.761 \\
\hline 13 & 49 & Mainfreight & N. Zealand & 1.227 & 13 & 47 & Logwin Ag & Luxembourg & 1.262 \\
\hline 15 & 45 & Wincanton & UK & 1.471 & & & & & \\
\hline 17 & 2 & Kuehna \& Nagel & Switzerland & 22.572 & & & & & \\
\hline 18 & 17 & Yusen Log. & Japan & 4.183 & & & & & \\
\hline 19 & 31 & Sankyu & Japan & 2.412 & & & & & \\
\hline 20 & 33 & Nippon Exp. & Japan & 2.368 & & & & & \\
\hline
\end{tabular}

EK 2. Kümele analizi dendogram grafiği

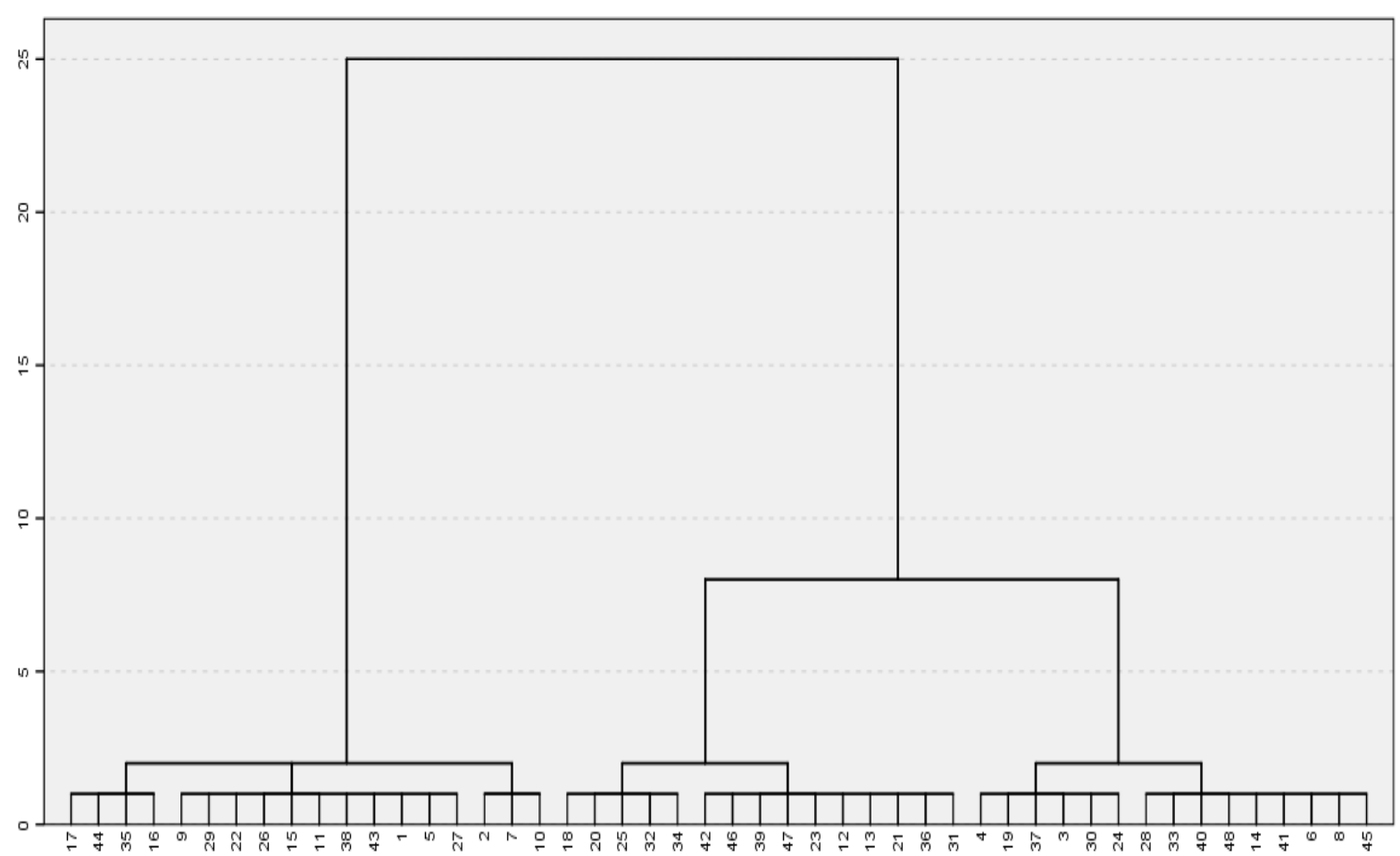


Şahin, E. E. \& Vergili, G.

Ek 3. Politik risk endeksi değerleri

\begin{tabular}{|l|l|c|c|c|c|c|c|}
\hline \multicolumn{1}{|c|}{ ÜLKELER } & KOD & $\begin{array}{c}\text { Anayasa ve } \\
\text { Hukuksal Düzen }\end{array}$ & Yolsuzluk & $\begin{array}{c}\text { Hükümet } \\
\text { Kalitesi }\end{array}$ & $\begin{array}{c}\text { Yatrimm } \\
\text { Profili }\end{array}$ & Demokratikleşme & $\begin{array}{c}\text { Politik İstikrar } \\
\text { ve Şiddet }\end{array}$ \\
\hline Australia & AUS & 1 & 0,72 & 1 & 1 & 0,92 & 0,75 \\
\hline China & CHN & 0,38 & 0,62 & 0,5 & 0,45 & 0,58 & 0,33 \\
\hline Denmark & DNK & 1 & 0,63 & 1 & 0,59 & 1 & 0,92 \\
\hline France & FRA & 0,96 & 0,57 & 0,75 & 0,59 & 0,83 & 0,75 \\
\hline Germany & DEU & 1 & 0,77 & 1 & 0,91 & 0,83 & 0,83 \\
\hline Japan & JPN & 0,83 & 0,75 & 1 & 0,95 & 0,83 & 0,75 \\
\hline Kuwait & KWT & 0,67 & 0,7 & 0,5 & 0,73 & 0,67 & 0,5 \\
\hline Luxembourg & LUX & 1 & 0,83 & 1 & 0,91 & 1 & 0,83 \\
\hline Netherlands & NLD & 1 & 0,79 & 1 & 0,86 & 1 & 0,83 \\
\hline New Zealand & NZL & 1 & 0,76 & 1 & 1 & 0,92 & 0,92 \\
\hline South Africa & ZAF & 0,83 & 0,69 & 0,5 & 0,55 & 0,33 & 0,42 \\
\hline Switzerland & CHE & 1 & 0,81 & 1 & 0,95 & 0,83 & 0,83 \\
\hline United Kingdom & GBR & 1 & 0,7 & 1 & 0,95 & 0,83 & 0,83 \\
\hline United States & USA & 0,83 & 0,74 & 1 & 1 & 0,83 & 0,75 \\
\hline Luxembourg & LUX & 1 & 0,83 & 1 & 0,91 & 1 & 0,83 \\
\hline Hong Kong & HK & 0,38 & 0,78 & 0,5 & 0,64 & 0,67 & 0,42 \\
\hline
\end{tabular}

